\title{
A EXPRESSÃO REGIONAL DAS UNIVERSIDADES PÚBLICAS NAS CIDADES MÉDIAS DE SOBRAL-CE E PARNAIBA-PI ${ }^{1}$
}

\author{
Virgínia Célia Cavalcante de HOLANDA ${ }^{2}$
}

\section{Resumo}

As cidades de Sobral e Parnaíba são pensadas nesse artigo como cidades médias do Nordeste Brasileiro, a distância entre elas é de $252 \mathrm{~km}$, tem na história de formação e no dinamismo do presente aconteceres e usos que as aproximam. Sendo a expansão do Ensino Superior público e privado uma das variáveis de grande força no espaço urbano regional do período atual. Por entender que a universidade pública é historicamente a de maior penetração no cenário regional e pela necessidade de síntese, selecionamos o Campus da Universidade Federal do Piauí (UFPI) e em Sobral selecionamos a Universidade Estadual Vale do Acaraú (UVA), ambas ofertam Ensino Superior Público a mais de quatro décadas. Os procedimentos metodológicos foram pesquisa bibliográfica, pesquisa documental, trabalho de campo e entrevista com gestores.

Palavras chaves: Cidades Médias. Nordeste Brasileiro. Universidades Públicas.

\section{THE REGIONAL EXPRESSION OF THE PUBLIC UNIVERSITIES IN THE MEDIUM CITIES OF SOBRAL-CE AND PARNAIBA-PI}

\begin{abstract}
Sobral and Parnaíba are thought of in this article as medium cities of the Northeast of Brazil, located at a distance of $252 \mathrm{~km}$ from each other, has in the history of formation and dynamism of the present happenings and uses that approach them. The expansion of public and private higher education is one of the variables of great strength in the regional urban space of the current period. To understand that the public university is historically the one with the greatest penetration in the regional scenario and for the need of synthesis, we selected the Campus of the Federal University of Piauí (UFPI) and in Sobral we selected the State University of Vale of Acaraú (UVA), both offer Public Higher Education to more than four decades. The methodological procedures were bibliographic research, documentary research, field work and interview with managers.
\end{abstract}

Key words: Medium Cities. Brazilian Northeast. Public Universities.

\footnotetext{
${ }^{1}$ O Artigo faz parte da pesquisa que desenvolvemos sobre “ A expansão do Ensino Superior nas Cidades Médias Nordestina e conta com apoio financeiro da Fundação Cearense de Apoio ao Desenvolvimento Científico e Tecnológico (FUNCAP).

${ }^{2}$ Professora associada da Universidade Estadual Vale do Acaraú em Sobral e professora colaboradora do Programa de Pós-Graduação em Geografia da UECE. E-mail: virginiaholand@ hotmail.com.
} 


\section{LA EXPRESIÓN REGIONAL DE LAS UNIVERSIDADES PÚBLICAS EN LAS CIUDADES MEDIA DE SOBRAL-CE Y PARNAIBA-PI}

\section{Resumen}

Sobral y Parnaíba son pensadas en ese artículo como ciudades medias del Nordeste Brasileño, localizadas a una distância de $252 \mathrm{~km}$ una de la otra, tiene en la historia de formación y en el dinamismo del presente sucederes y usos que las aproximan. Siendo la expansión de Enseñanza Superior pública y privada una de las variables de gran fuerza en el espacio urbano regional del período actual. Por entender que la universidad pública es históricamente la de mayor penetración en el escenario regional y por la necesidad de síntesis, seleccionamos el Campus de la Universidad Federal de Piauí (UFPI) y en Sobral seleccionamos la Universidad Estatal Vale do Acaraú (UVA), ambas ofertam la enseñanza superior pública a más de cuatro décadas. Los procedimientos metodológicos fueron investigación bibliográfica, investigación documental, trabajo de campo y entrevista con gestores.

Palabras claves: Ciudades Medias. Nordeste brasileño. Universidades Públicas.

\section{INTRODUÇÃO}

O artigo faz parte das reflexões que estamos desenvolvendo sobre as cidades médias de Sobral no Noroeste cearense e Parnaíba no norte piauiense. (Figura 01). Assim, vincula-se às nossas inquietações e conseqüente necessidade de se refletir sobre a inserção desses lugares em uma lógica globalizante, por meio das atividades turísticas, da modernização dos serviços e dos novos fluxos de pessoas, produtos e capitais. Nessa análise nos debruçamos mais detidamente na leitura do papel de duas instituições de ensino superior para as dinâmicas e potencialidades das cidades estudadas no espaço urbano regional.

A ligação histórica entre o Noroeste Cearense e Norte Piauiense é reforçada na atualidade, pelas novas dinâmicas das atividades industriais, de comércio e de serviços que têm levado o poder público a buscar novos investimentos de forma consorciada com ações integradas entre os estados, resultando na criação de amplos sistema de objetos técnicos, consubstanciando a racionalidade no uso do território, que se materializa por exemplo, na ampliação da malha viária, construção de aeroportos, construção das Zonas de Processamento de Exportações (ZPE), entre outros. 
Figura 01 - Localização de Parnaíba (PI) e Sobral (CE)

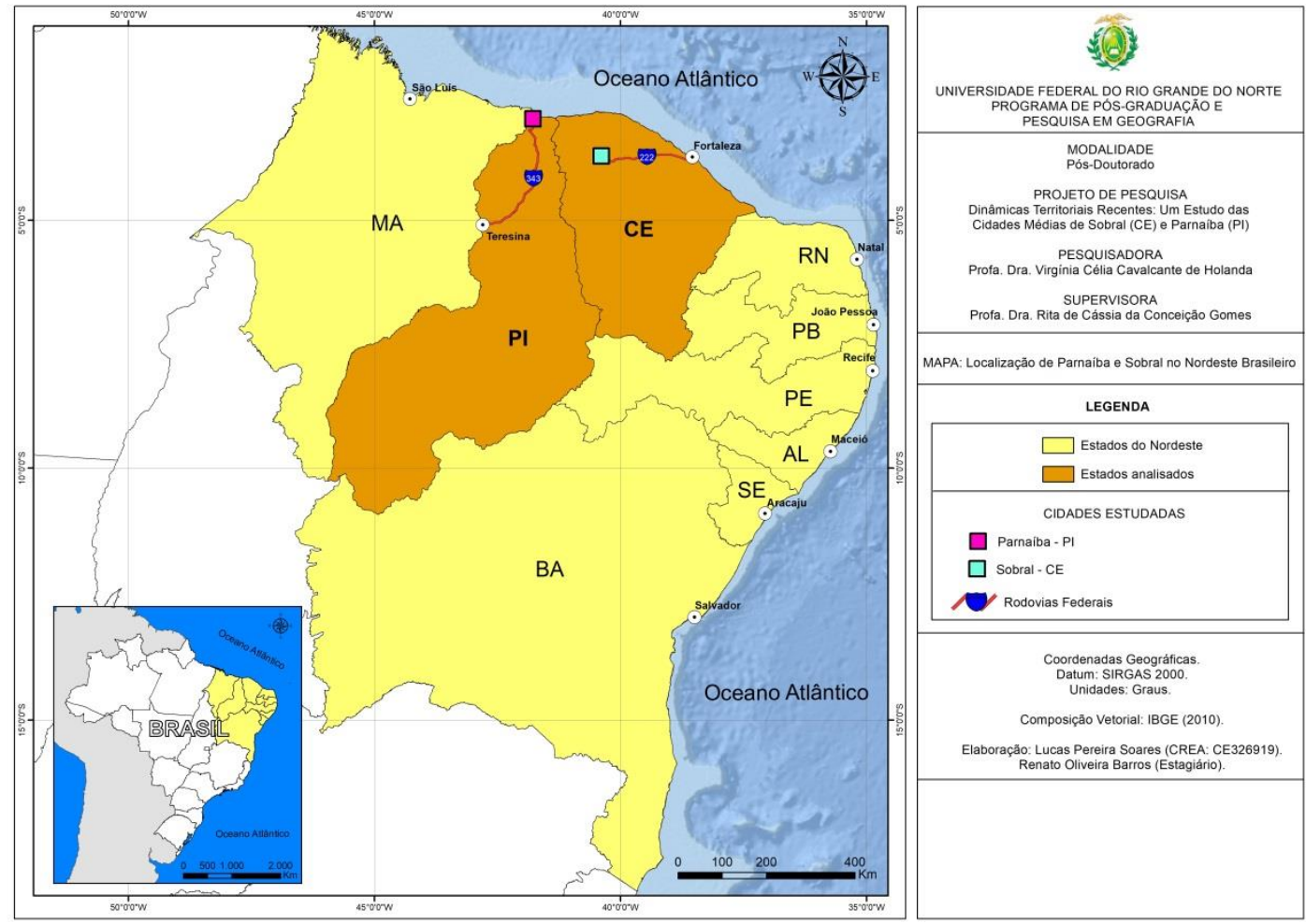

Sobral e Parnaíba tornaram-se, nos últimos anos, atrativas para o desenvolvimento de atividades produtivas e setores mais especializados nas áreas: de educação, saúde e administração pública. Como suportes às novas atividades ampliaram-se, ainda, as redes técnicas e informacionais. Nesse contexto a Expansão do Ensino Superior nessas cidades apresenta-se crescentemente como umas das atividades mas dinamizadoras do espaço urbano e regional. No intuído de entender a força dessa atividade selecionamos em Parnaíba o campus Reis Veloso que recém se desmembrou da Universidade Federal do Piauí, tornada Universidade do Delta do Parnaíba (UFDPar), por meio do projeto de lei 5.272 de 2016 e aprovada pela Câmara dos Deputados em 20 de Março de 2018, por tanto ainda em transição. Na cidade de Sobral elegemos a Universidade Estadual Vale do Acaraú (UVA), que completa seu jubileu em 2018 como o maior fixo de oferta de Ensino Superior no Noroeste cearense, ambas as instituições são originárias de faculdades católicas.

Para entender a expressão dessas duas instituições, lançamos mão de entrevistas com os gestores das referidas instituições, diário de campo das conversas com professores, visitas técnicas com registros fotográficos e filmagens, consulta aos dados e informações disponíveis na Internet, entre outros. 
Inferimos que o papel dessas cidades médias e as dinâmicas por elas vivenciadas constitui elementos chaves para o entendimento das novas formas de apropriação e configurações territoriais do espaço nordestino.

A distancia entre Sobral e Parnaíba é de 252 km, o que propicia relações entre elas, sobretudo no âmbito do Ensino Superior e dos serviços de saúde mais especializados, onde a malha rodoviária aparece como um dos fatores que facilita o fluxo e a integração entre as áreas de influencias dessas cidades. Cidades como Camocim, no território cearense exatamente no meio da distancia entre as duas, enviam no turno da noite três ônibus com universitários para Sobral e dois para Parnaíba.

A dinâmica verificada nas cidades médias no Nordeste, não obstante o poder centralizador das metrópoles e capitais regionais deve-se tanto a condição que assumiram no processo histórico de formação do sistema de cidades quanto às transformações econômicas, políticas e sociais vivenciadas na sociedade nordestina como um todo e no âmbito nacional e global.

As transformações do capitalismo internacional atingem de diferentes formas os lugares. Algumas análises tratam estas mudanças, advindas em parte da globalização e como oposição entre local e global. Optou-se por uma perspectiva analítica que pensa dialeticamente a relação global e local, em um jogo de forças no qual é possível à apreensão das mudanças.

$\mathrm{O}$ artigo encontra-se estruturado em três itens: o primeiro correspondendo a essa introdução, o segundo consiste em uma pequena reflexão sobre o conceito de cidade média, o terceiro analisa os papéis de Parnaíba e Sobral enquanto cidades médias com expressão na oferta de Ensino Superior e o ultimo sendo as considerações finais.

\section{CIDADES MÉDIAS: NOTAS TEÓRICAS E METODOLÓGICAS}

A questão metodológica consiste, em primeiro lugar, na definição dos termos conceituais, como ponto de partida. A cidade média constitui uma realidade devendo ser pensada não só em uma dimensão, de certa forma já histórica, mas em face da reestruturação engendrada a partir do novo paradigma técnico-econômico. Nessa assertiva é que pensamos como as cidades médias são afetadas pelo processo de reestruturação e mundialização da economia, entendendo como reestruturação o movimento de ruptura e mutações na perspectiva de Soja que define a reestruturação como desaceleração ou ruptura do que já 
existe secularmente envolvendo uma "[...] mudança em direção a uma ordem e uma configuração significativamente diferente da vida social, econômica e política" (SOJA, 1993, p. 193).

Analisar, entender e explicar os processos subjacentes à lógica territorial urbana requer procedimentos inseridos em raciocínios para além do quantitativo e do empírico, ou seja, demanda um pensamento dialético na condução da reflexão sobre o objeto. Para tanto, cabe elucidar conceitos e estabelecer diretrizes bem como as variáveis operacionais construindo-se, assim, os caminhos da pesquisa.

A divisão das cidades em pequenas, médias e grandes constitui uma primeira classificação das aglomerações urbanas no sentido empírico e de formulação de tipologias. A esse respeito, Lamarre, ao discutir o surgimento do conceito de cidade média, afirma ser esta divisão do urbano simultaneamente pretérita e recente. Pretérita porque encontra-se adaptada ao vocabulário corrente visto que exprime empiricamente as dimensões de um fenômeno. Quanto a ser recente deve-se ao fato de não apresentarem muitas vezes as mesmas características das cidades que são utilizadas com as mesmas referências.

Como toda taxonomia, aquelas que se aplicam às cidades têm uma dupla origem: a observação do fenômeno, um pressuposto, uma concepção da cidade, de sua essência, de suas funções, de seu papel. (LAMARRE, 1997 p. 38).

Com base em estudos realizados pelo Instituto de Pesquisa Econômica Aplicada (IPEA), as cidades médias brasileiras são aquelas que, de acordo com os dados do Censo de 1991, contam com uma população urbana entre 100 mil e 500 mil habitantes. Já para a Organização das Nações Unidas (ONU) as cidades médias são aquelas com população entre 100 mil e um milhão de habitantes. (TOMAS, 1998).

Alguns autores relativizam o conceito de cidade média, a exemplo de Barat, que a define a partir das suas relações com o mundo e na sua dimensão no sistema nacional de cidades em que está inserida.

O conceito que caracteriza a cidade média é, portanto relativo em dois planos. Ele o é em relação às ligações que a cidade estabelece no sistema mundial [...] e é relativo quanto à dimensão geral do sistema nacional em que se encontra. (BARAT, 1979 p. 119).

A relação entre o crescimento da cidade média e o aumento populacional urbano está no cerne das preocupações conceituais. A propósito, Commerçon (1998) em seu estudo sobre a dinâmica das cidades médias francesas de Chalon, Mâcon e Bourg, levanta questões como: 
O aumento da população residindo em cidades médias representa mudança numérica ou estrutural? O crescimento quantitativo e espacial da cidade média responde em corolário ao enfraquecimento de outros espaços em detrimento do qual a cidade nasceu?

Obviamente estas questões estão direcionadas para a realidade francesa, cuja história da urbanização é outra e onde a sociedade já se acha desde o século XIX urbanizada, fazendo com que as cidades médias tenham importante papel no processo de produção do espaço. No caso brasileiro não podemos generalizar, ou seja, enfocar as cidades médias no seu sistema urbano como um todo, cabendo melhor precisar o papel das cidades médias nos contextos territoriais urbanos sejam estaduais ou regionais. Por certo serão encontradas nas análises dos vários territórios similitudes e diferenças resultantes não só das transformações no padrão demográfico, mas, sobretudo, das mutações econômicas e sociais.

A cidade média ao ser definida segundo uma hierarquia, ou seja, em relação à metrópole e as cidades menores, situando-se, portanto, em um nível intermediário em termos demográficos, varia segundo a região e/ou país e o período considerado. A propósito, Santos levanta a questão: podem-se classificar cidades com mais de 20 mil habitantes como média? E responde colocando o problema das estatísticas para as ciências humanas, dado que o número possui significados diferentes em momentos diferentes e o que pode ser chamado de cidade média na década de 1940/1950 não o é mais na década de 1970/1980. Acrescenta ainda que na década de 1990 - quando foram feitas estas (re) formulações - para ser considerada cidade média, uma aglomeração deveria ter em torno de 100 mil habitantes. (SANTOS, 1994).

A definição de cidade média baseada no critério populacional varia conforme a época, isto é, a década considerada. Varia, também, no caso brasileiro, conforme a região e/ou estado. O limiar de uma cidade média no Ceará, não é o mesmo de uma cidade no estado de São Paulo. Este critério deve ser considerado, porém não é suficiente para definir as cidades médias.

O impasse sobre a definição de cidade média levou o geógrafo francês Brunet a propor três temas: "o entorno do objeto - o contexto; a cidade média no sistema de cidades, isto é, para além da cidade; e a cidade média no sistema geográfico local - em torno dela mesma" (1997, p. 13). Contudo é em grande parte nessa relação da cidade com o seu território e para além da cidade, que Brunet considera o interesse pela cidade média enquanto objeto a ser pesquisado. A busca de uma definição para as cidades médias vincula-se, assim, a um outro nível de compreensão do urbano enquanto objeto geográfico, cabendo aos pesquisadores 
indagarem sobre o significado da cidade média não como entidade isolada, mas como elemento de um território ou de um sistema de cidades.

Fica, assim, evidente que o conceito, ou mesmo a definição de cidades médias não está restrito ao tamanho populacional nem tampouco restrito às suas funções. Corrêa (2007) reforça a dificuldade de se conceituar cidade média, afirmando a necessidade de um esforço de abstração para se estabelecer a unidade do que é pouco conhecido, porém bastante diversificado.

Trazendo esta reflexão para o território nordestino convém ressaltar os novos papéis que assumem estas cidades face "as transformações ocorridas no mundo capitalista" conforme nos lembra Pontes (2007, p.334). Ainda de acordo com a autora:

[...] a cidade média seria um centro urbano com condições de atuar como suporte às atividades econômicas de sua hinterlândia, bem como atualmente ela pode manter relações com o mundo globalizado, constituindo com este uma nova rede geográfica superposta a que regularmente mantém com suas esferas de influência. Esta segunda rede [...] diz respeito ao sistema de relações realizadas sobre o território com áreas rurais ou outras cidades próximas ou mais distantes sobre as quais ela exerce uma condição de comando (2007, p.334)

No dialogo com esses autores entendemos ser a cidade média no plano de escala, aquela cidade que não é uma metrópole nem uma cidade pequena, mas uma aglomeração urbana significativa em termos demográficos, em funcionalidade e em relação a sua região, expressando e gerando certo dinamismo econômico, social, político, etc.;

Assim, é na base territorial que se busca o nexo entre os espaços de atuação das cidades médias de Sobral e Parnaíba, levando-se em conta a ligação histórica entre o Noroeste Cearense e o Norte Piauiense. Esta ligação é reforçada, na atualidade, pela atividade turística que tem levado o poder público a buscar novos investimentos de forma consorciada entre os estados. O resultado é a criação de objetos técnicos, consubstanciando a racionalidade no uso do território.

\section{PARNAÍBA E SOBRAL ENQUANTO CIDADES MÉDIAS DO NORDESTE BRASILEIRO: A EXPRESSÃO DO ENSINO SUPERIOR}

Parnaíba e Sobral são tradicionais centros regionais do Nordeste Brasileiro e nos estudos de Região de Influência das Cidades (Regic, 2008), Paranaíba apresenta-se como Centro-sub regional "A" ao lado de Picos e Floriano no Piauí. Esse nível de centro divide-se em A e B e abriga 169 cidades em todo território brasileiro, com atividades de gestão 
consideradas menos complexas, em sua grande maioria dentro dos níveis 04 e 05 da gestão territorial.

Quanto a Sobral aparece na Regic como capital regional "C", são 70 centros urbanos que agregam este nível. Sua capacidade de gestão sendo inferior ao das metrópoles, mas um conjunto considerável de cidade menores buscam sua oferta de atividades. Apresenta três subdivisões. O primeiro grupo (Capital Regional A) inclui as capitais estaduais não classificadas no nível metropolitano e Campinas. O segundo e o terceiro, composto pelas Capitais Regionais B e C, além da diferenciação de tamanho, têm arquétipo de localização regionalizado, com o segundo mais presente no Centro-Sul, e o terceiro nas demais regiões do País, a exemplo do Ceará que abriga além de Sobral as cidades do Chamado CRAJUBAR Crato, Juazeiro do Norte e Barbalha (Quadro 01).

\begin{tabular}{|c|c|c|}
\hline HIERARQUIA URBANA & CIDADES DO PIAUÍ & CIDADES DO CEARÁ \\
\hline Metrópole & - & Fortaleza \\
\hline Capital regional A & Teresina & \\
\hline Capital regional B & - & \\
\hline Capital regional $\mathrm{C}$ & - & Crato, Juazeiro do Norte, Barbalha, Sobral \\
\hline Centro sub-regional A & Floriano, Picos, Parnaíba & Crateús, Iguatu, Quixadá \\
\hline Centro sub-regional B & São Raimundo Nonato, Campo Maior & Itapipoca \\
\hline Centro de zona A & $\begin{array}{c}\text { Bom Jesus, Corrente, Esperantina, Oeiras, } \\
\text { Piripiri }\end{array}$ & $\begin{array}{c}\text { Acaraú, Aracati, Canindé, Limoeiro do } \\
\text { Norte, Russas, Icó }\end{array}$ \\
\hline Centro de zona B & $\begin{array}{l}\text { Agua Branca, Alto Longá, Amarante, } \\
\text { Barras, Canto do Buriti, Luzilândia, Pedro } \\
\text { II, São João do Piauí, Valença do Piauí, } \\
\text { União, Curimatá, Avelino Lopes, Gilbués, } \\
\text { Piracuruca, Santa Filomena, Castelo do } \\
\text { Piauí, São Miguel do Tapuio, Anísio de } \\
\text { Abreu, Caracol, Uruçui, Fronteiras, Jaicós, } \\
\text { Paulistana }\end{array}$ & $\begin{array}{l}\text { Iracema, Itapagé, Jaguaribe, Tauá, Cruz, } \\
\text { Senador Pompeu, Brejo Santo, Camocim, } \\
\text { Guaraciaba do Norte, Ipu, São Benedito }\end{array}$ \\
\hline
\end{tabular}

Fonte: Regiões de Influência das Cidades (2008). Obs. As demais cidades de cada Estado que não se encontram na lista são considerados Centros Locais.

Pensamos Sobral e Parnaíba enquanto cidades médias Nordestinas, que não mais se restringem a centros coletores da produção regional e à condição de centros beneficiadores de produtos agrícolas a exemplo do algodão, produto que praticamente desapareceu da economia cearense a partir da década de 1970 ou a produção do charque importante no século XIX, para os dois núcleos. Nos anos de 1980, as cidades médias da região reforçam a condição de centros terciários ampliando as atividades de comércio e serviços além da absorção de 
indústrias subsidiadas, alterando, assim, a divisão social e territorial do trabalho por não estarem apenas calcadas nas relações cidade e campo.

Os estudos sobre tais cidades devem estar calcados numa concepção, em rede, da cidade e da região, numa perspectiva que priorize, mais do que a dimensão demográfica, o modo como a cidade média articula suas relações com os demais componentes do sistema urbano. Sposito (2007) ressalta o papel regional que esse tipo de cidade desempenha associada ao potencial de comunicação e articulação proporcionado por suas situações geográficas.

As cidades médias são consideradas em muitos países, como centros urbanos capazes de promover um maior equilíbrio territorial urbano, utilizadas como ideais para implantação de investimentos econômicos mais modernos. São idealizadas como locais favoráveis a uma melhor qualidade de vida, haja vista os problemas que afligem comumente os habitantes das grandes metrópoles. Destacam-se, ainda, por serem centros que estabelecem relações mais diretas com o entorno territorial.

Em termos gerais, as cidades médias de Parnaíba e Sobral apresentam características urbanas que possibilitam sua influência numa área circundante. Cabe destacar que essas cidades estabelecem relações não só entre as pequenas e grandes cidades de sua região, mas também com o meio rural e regional no qual estão inseridas.

Na década de 1980, mais precisamente em sua segunda metade, tem início um novo período na formação espacial do Nordeste brasileiro, marcado por transformações políticas, econômicas e sociais, imprimindo novas dinâmicas e configurações territoriais, baseadas na lógica política da racionalidade administrativa e econômica e nos preceitos do neoliberalismo.

A partir da segunda metade dos anos de 1990 e na primeira década do século XX investimentos significativos foram carreados para a região Nordeste na esteira dos incentivos fiscais. A maior parte dos investimentos dirigiu-se às regiões metropolitanas e as cidades médias, elevando-se, assim, as taxas de crescimento econômico. Em Sobral o Produto Interno Bruto registrou para o ano de 2013, a seguinte situação em termos percentuais: serviços 66,36 $\%$, indústrias $32,84 \%$ e agropecuária: $0.80 \%$.

Depois de 2010 novos investimentos que tiveram como vetores a indústria, a atividade turística e modernização da atividade comercial e de serviços vêm provocando impactos no mercado de trabalho e Alterando novas formas comerciais a exemplo da implantação de shopping centers: Parnaíba Shopping e Dunnas Shopping em Parnaíba e North Shopping em 
Sobral. Situação acompanhada da construção de novos fixos, com destaque para: o saneamento básico que em Parnaíba alcança 90\% de seu território, em Sobral chama atenção a intensidade de abertura e pavimentação de novas vias de circulação e a implantação do Veiculo leves sobre trilhos. Tudo isso contribuiu para tornar as referidas cidades mais atrativas não só para o desenvolvimento de atividades produtivas e de serviços, mas também para a vinda de migrantes de diferentes origens, ampliando consideravelmente os problemas de desemprego, falta de moradia e de equipamentos de saúde e educação, problemas estes antes mais presentes nas grandes cidades.

Em 2009, Parnaíba foi destaque como cidade mais dinâmica do estado do Piauí, sendo a $5^{\mathrm{a}}$ na região Nordeste e a $32^{\mathrm{a}}$ do Brasil e em 2011, é destaque com maior crescimento, registrando um índice de $229 \%$ em relação ao ano anterior. Apresenta em 2014, um percentual de 4,41\% no PIB estadual, com destaque para o setor Serviços com 86,59\% na economia municipal, em termos proporcionais sendo a participação dos serviços superior o da capital Teresina, cuja participação dos serviços foi de $76,31 \%$ no mesmo ano. No estado do Ceará no quadro econômico estadual, são poucos os espaços urbanos que vem se consolidando economicamente, predominantemente, os municípios da região metropolitana de Fortaleza e poucos municípios do interior, com destaque para Sobral que assim como Parnaíba vivencia um quadro de expansão dos serviços, onde seu PIB aparece com incremento de 52,75 de 2011 para 2015. (tabela 01). Sobral e a quarta economia do Estado depois da metrópole Fortaleza e dos municípios de Maracanaú e Caucaia pertencentes a região metropolitana de Fortaleza.

Tabela 01: PIB da Cidade de Sobral por atividade Econômica (2011 e 2015)

\begin{tabular}{c|c|c}
\hline Atividade & $\mathbf{2 0 1 1}$ & $\mathbf{2 0 1 5}$ \\
\hline Agropecuária & $1,56 \%$ & 0,80 \\
\hline Indústria & $30,27 \%$ & 28,64 \\
\hline Serviços & $68,14 \%$ & 70,57 \\
\hline PIB Total Absoluto & 2.671 .208 & 4.080 .276
\end{tabular}

Fonte: IPECE (Perfil Básico Municipal), 2014. Elaboração: HOLANDA, 2014

Não obstante, as duas cidades tiveram seu Patrimônio Histórico (re) valorizado juntamente com uma significativa reforma urbana, construção do plano de diretor, construção de aterro sanitário, etc.; o que tem servido como marketing para realçar essas cidades como 
lugares atrativos e dotadas de condições favoráveis aos novos empreendimentos como também a uma boa qualidade de vida.

Parnaíba, cidade mais importante do estado do Piauí depois da capital Teresina, apresenta características parecidas com Sobral conforme já se fez menção, no que concerne a urbanização e a dinâmica de sua população. Para o ano de 2010 a população de Parnaíba contabilizou 145.705 habitantes com projeção de 150.547 em 2016. Sobral apareceu com 188.233 habitantes em 2010 e estimativa de 203.682 em 2016. Quando analisada a taxa de crescimento anual no período dos dois censos do IBGE (2000-2010); Sobral figurou com o dobro da taxa geométrica anual de crescimento demográficos $1,94 \%$ contra $0,97 \%$ de Parnaíba, quanto a taxa de urbanização a de Parnaíba é 94,36\% e a de Sobral 88,35\%. Analisando o Índice de Desenvolvimento Humano as duas cidades médias estão muito próximas: Sobral com leve vantagem aparece com 0,714 e Parnaíba com 0,687.

Situada no delta do Parnaíba, área de grande potencial turístico, encontra na mesma uma das possibilidades de desenvolvimento no presente. Assim, como Sobral abriga campus do Instituto Federal E campus da Universidade Estadual do Piauí (UESPI) e se multiplicam pelo território faculdades privadas e institutos com oferta de cursos superior presencial e a distância. Nos últimos cinco anos se instalaram a Faculdade Internacional do Delta e Faculdade Mauricio de Nassau, essas duas estrategicamente nas artérias de saída da cidade.

Nesse sentido quando pensamos a presença do Ensino Superior nessas cidades advogamos que elas vem paulatinamente ajudando a mudar a face do seu espaço regional, tendo em vista que embora o ensino superior privado avance pelo território dessas cidades, há em paralelo a presença das universidades públicas, que por meio do ensino, pesquisa e extensão vem trilhando um maior alcance regional, provocando a possibilidade de redução de assimetrias no espaço regional. A fala das gestões das universidades estudadas revelam a universidade como elemento importante para o desenvolvimento regional;

Com a expansão universitária a partir de 2007 é inaugurada um novo momento da História de nosso campus. Baseado em uma pesquisa regional, ocorre a criação de sete novos cursos, (Turismo, engenharia de pesca, matemática, biologia, biomedicina, fisioterapia e psicologia), simultaneamente também ocorre a expansão de infra estrutura. Essa expansão do campus ajuda a transformar a cidade, só de custeio é algo em torno de seis milhões de reais por ano que circula, são quase cinco mil estudantes, onde $80 \%$ são de fora de Parnaíba, alcançando treze municípios da bacia do delta, envolvendo ai quase um milhão de habitantes de forma indireta. A criação dos cursos novos fez com que as faculdades particulares também se revitalizassem, hoje em Parnaíba temos algo em torno de 18 mil universitários. 
(ALEXANDRO MARINHO, Diretor do Campus Reis Veloso - UFPI, entrevista concedida a pesquisadora em 20 de março de 2017).

\begin{abstract}
A UVA é a principal formadora de recursos humanos, de líderes e de profissionais liberais da região, atendendo cerca de 54 municípios da região norte do Estado do Ceará. Isso tem uma implicação direta na oferta de pessoal qualificado ao mercado de trabalho. Sim. Hoje, Sobral conta com 05 instituições de ensino superior, sendo 03 públicas e 02 privadas, com fluxo diário aproximado de 20 mil alunos na graduação e pós-graduação dos municípios de abrangência da UVA e de outros estados vizinhos, o que caracteriza uma grande influência das Universidades no desenvolvimento da cidade. (FABIANNO CAVALCANTE DE CARVALHO, Reitor da Universidade Estadual Vale do Acaraú -UVA. Resposta concedida em 18 de Setembro de 2017).
\end{abstract}

A Universidade Estadual Vale do Acaraú (UVA) tem sua origem em 1961, porém, é especialmente na década de 1990 e nos anos 2000, que seu papel como importante centro universitário da região Norte do Estado do Ceará se consolida. Desde a época de sua fundação até os dias atuais a Universidade tem passado por expressivas mudanças em sua estrutura, contribuindo também para a transformação do espaço regional onde está inserida.

Atualmente oferece em Sobral 26 cursos, 13 bacharelados, 12 licenciaturas e uma graduação tecnológica, dois cursos de Mestrado Acadêmico: Geografia e Zootecnia. Um curso de Mestrado em Saúde da Família criado em Rede. No primeiro semestre de 2016, efetuou 9.869 matriculas. Na cidade de Sobral são quatro campi: Betânia, Derby, Junco e CIDAO. Percebe-se que a Universidade representa um objeto de modernização e transformação do espaço urbano sobralense, conto no ano de 2018 com quadro campus espalhado pela cidade: campus do Junco, campus da CIDAO, Campus do Derby e campus da Betânia.

Com relação às mudanças no papel da UVA dentro da região Norte, essas estão atreladas às ações do poder público principalmente do Governo do Estado do Ceará que vê no desenvolvimento das universidades um dos vetores de modernização do estado, embora a mais de 15 anos a universidade não oferte cursos novos.

A UVA ao se afirmar como a mais significativa instituição de desenvolvimento da região em que está inserida, abraça um papel institucional claro, o de formar profissionais mais qualificados para a renovação e melhoria dos quadros regionais, sobretudo no campo das licenciaturas, nos 55 municípios emissores de alunos para Sobral, todos tem no quadro da administração publica profissionais formados por essa IES.

Os estudantes segundo dados da própria Universidade para ano de 2016.1, cerca de $66 \%$ dos estudantes moram em Sobral, os demais são provenientes de 55 municípios e 
retornam todos os dias para suas residências. (Figura 02). O percentual relevante de estudantes residentes em Sobral, revelamque muitos não são naturais de Sobral, mas sim alunos que para contornar a barreira do deslocamento diário entre seus municípios de origem e a Universidade, decidem residir na cidade.

Figura 02 - Procedência dos Estudantes 2016.1

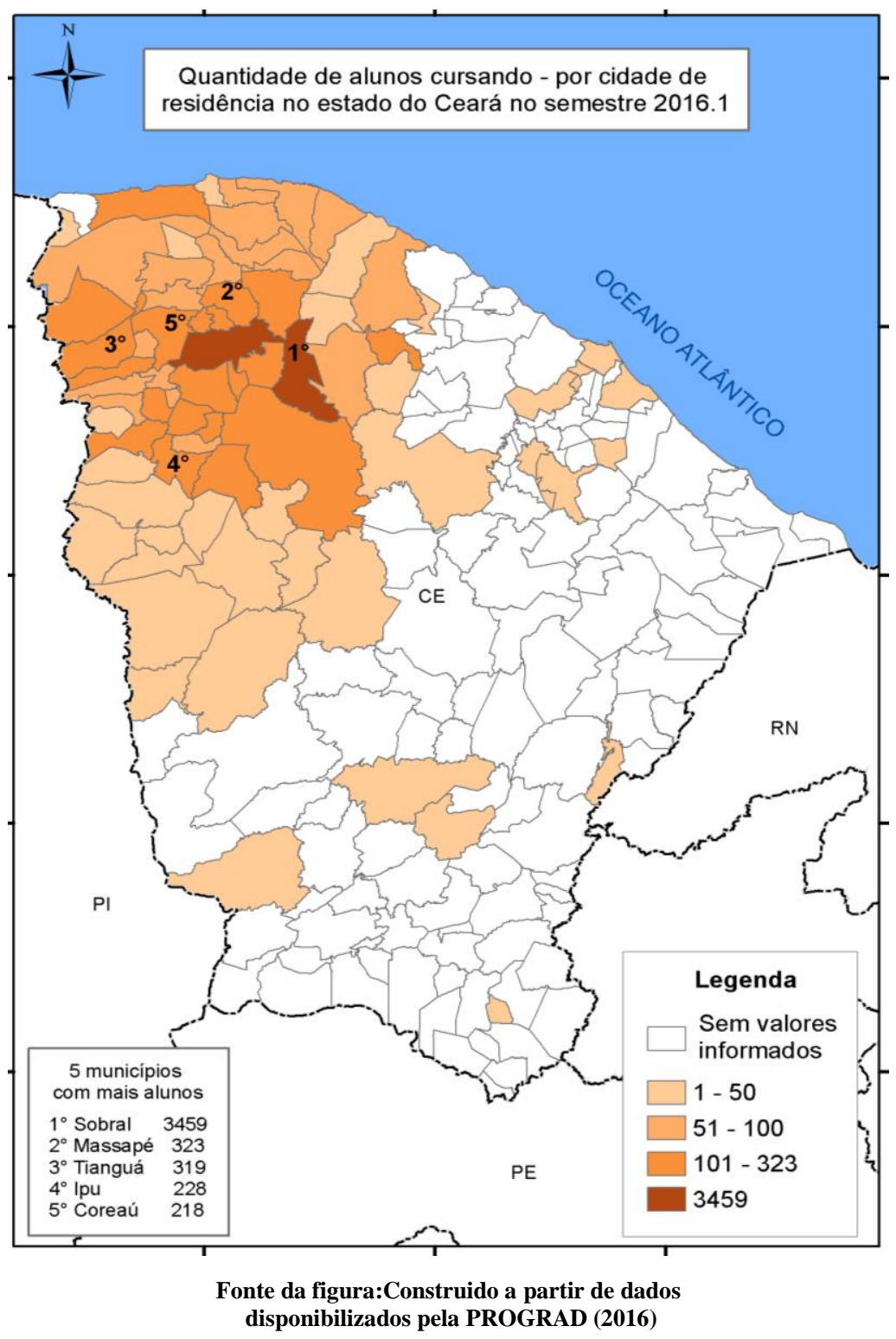

Esses deslocamentos pendulares ocorrem em sua maioria por meio de ônibus cedidos pelas prefeituras dos municípios que diariamente chegam a Sobral nos turnos manhã e noite. Verificamos, assim, em Sobral, uma complementaridade na economia devido a estes migrantes pendulares, pois além de movimentarem o setor de educação da cidade, estimulam 
também o comércio em geral. O que vem chamando atenção é que crescentemente o aluno formado retorna ao seu município de origem, situação constatada quando em visitas nas cidades pequenas vizinhas a Sobral, onde verificamos a presença de escritórios de advocacia, contabilidade, de serviço de engenharia, comércios administrados por pessoas formadas, academias de ginásticas, etc.; Os editais de concursos das prefeituras exigem cada vez mais profissionais com diploma de nível superior. Se contata ainda parte significativa de gestores municipais do noroeste cearense que também se formaram na UVA, conforme reitera a fala do reitor;

\begin{abstract}
Grande parte dos gestores municipais são formados pela UVA. Isto facilita a construção de parcerias e convênios nas mais diversas áreas do conhecimento e conduzem para o desenvolvimento dos municípios e fortalecimento da Universidade. (FABIANNO CAVALCANTE DE CARVALHO, Reitor da Universidade Estadual Vale do Acaraú -UVA. Resposta concedida em 18 de Setembro de 2017).
\end{abstract}

A implantação do campus da Universidade Federal do Piauí em Parnaíba tem seu surgimento ligado a antiga Faculdade de Administração do Piauí, A construção do campus em 1971, recebeu o nome de Reis Veloso em homenagem ao economista e ministro do planejamento no período de 1969 a 1979, de Parnaíba. O curso de Administração sendo o primeiro e nos anos seguintes foram criados os cursos: de Ciências Contábeis, Ciências Econômicas e Pedagogia. Somente nos primeiros anos da década de 1990 passa a se organizar como unidade acadêmica nos moldes da UFPI, com estrutural departamental: Ciências da Administração e Informática, de Ciências Sociais da Educação e do Desporto, de Ciências Contábeis e Jurídicas e Ciências Econômicas e Quantitativas. Começa também a oferta de pós-graduação em nível de Especialização.

A grande virada no campus sendo depois de 2007 com a criação Programa de Apoio a Planos de Reestruturação e Expansão das Universidades Federais (REUNI), dentro do Plano de Desenvolvimento da Educação (PDE). O campus Reis Veloso tem outra guinada como Universidade do Delta do Parnaíba (UFDPar) no primeiro semestre de 2018 conforme colocado anteriormente, é centro de referência no Ensino Superior em toda sua área de influência, implantou em 2014 o curso de medicina. Em 2018.1 oferta doze cursos de graduações: Biologia, Biomedicina, medicina, Fisioterapia, Psicologia, Administração, Ciências Contábeis, Economia, Turismo, Pedagogia, Engenharia de Pesca e Matemática. Oferta também um curso de mestrado em arte, patrimônio e museologia. Conta com duzentos e quarenta e dois professores e oitenta e oito técnicos administrativos efetivos. O curso de 
medicina foi criado dentro da compreensão do papel regional desempenhado pela universidade, conforme revela o diretor;

Todas as prefeituras se envolveram para trazer o curso de medicina, por meio de apoio político dos prefeitos da região, eles buscaram recursos das emendas parlamentares de seus deputados, foram dezesseis milhões oriundos de emendas. (...) (ALEXANDRO MARINHO, Diretor do Campus Reis Veloso - UFPI, entrevista concedida a pesquisadora em 20 de março de 2017).

As universidades públicas no presente continuam a apresentar importante papel na tentativa de contribuir com a melhora das condições de vida da região, como já se defendia nos idos de 1980;

Creio deva-se inicialmente, reconhecer a inestimável contribuição que as universidades do Nordeste vêm dando ao desenvolvimento da Região, na capacitação de recursos humanos, na pesquisa, na formação da consciência critica dos problemas regionais, na ampliação e difusão da cultura, na permanente, múltipla interação que estabelece com a sociedade. (ALBUQUERQUE, 1980, p. 23)

As duas universidades públicas apresentam papel de destaque ancorados também pelas atividades de pesquisa e extensão o que ainda não é uma prática nas instituições de ensino superior particulares, por isso optamos por escutar a fala de seus gestores e observamos algumas ações de extensão. Para o Prof. Alexandro Marinho a aproximação junto a comunidade vem correndo em todos cursos, mas sobretudo pelas práticas crescente de extensão dos cursos de saúde, educação, engenharia de pesca e turismo. Para o ano de 2016, 55\% das bolsas de extensão de toda Universidade Federal do Piauí ficou no campus Reis Veloso em Parnaíba, denotativo do trabalho de extensão realizado.

Na Universidade Estadual Vale do Acaraú (UVA) as ações, projetos e programas de extensão ainda são tímidos e concentrados no próprio espaço urbano de Sobral. A atuação sendo destaque para a área da saúde. Acreditamos que o alcance da extensão, assim como a pesquisa são dimensões que carecem de uma caracterização nas duas instituições estudadas, elas certamente nos ajudarão no futuro na verificação das tendências de alcance e seus rebatimentos regionais.

\section{CONSIDERAÇÕES FINAIS}

A busca por uma compreensão das transformações das cidades médias e seus rebatimentos urbano regional pela força das universidades públicas, nos permite inferir que se 
constrói novos nexos entre cidades de diferentes escalas, com maior possibilidade da cidade média não replicar as assimetrias recorrente na rede urbana tradicional, onde espaços mais dinâmicos asfixiam os espaços do entorno.

Em nossa análise, percebemos que a concentração de investimentos públicos e privados na abertura de vagas no ensino superior atrai um significativo contingente de pessoas que almejam formação universitária e qualificação profissional para atuarem nos seus lugares de origem. Com a instalação de unidades de ensino superior, as cidades médias nordestinas vão se destacando como principal centro educacional no seu espaço urbano regional, atendendo também aos Estados vizinhos.

A função educacional ao longo do tempo foi se consolidando e, sempre foi um fator preponderante no papel regional exercido pela cidade. Assim, compreendemos que o aumento e a diversificação dessas atividades ditas não produtivas, vão se materializando no espaço geográfico, reforçando e criando hierarquias urbanas e também novas articulações marcadas não necessariamente pelas contiguidades, mas também reforçam horizontalidades.

No contexto de reestruturação da economia, da política e da sociedade, o papel polarizador dessas cidades é ampliado por um lado, com uma maior atração de migrantes procedentes de suas respectivas áreas de influencias elevando-se assim as taxas de urbanização e crescentes desigualdades espaciais, permeada pela recente especulação imobiliária, onde não se identifica um padrão espacial de expansão, nas duas cidades sendo edificada para todos os lados.

Por outro lado as instalações de novos equipamentos públicos e privados contribuem para atrair uma mão de obra cada vez mais especializada, voltada para as atividades produtivas e a prestação de serviços a exemplo do Ensino Superior que conta hoje com três instituições de Ensino Superior Público: Campus avançados do Instituto Federal e da Universidade Federal do Ceará e a Universidade Estadual Vale do Acaraú. Na esfera privada Sobral além dos inúmeros cursos de Educação Superior na modalidade a distancia, abriga um Centro Universitário Inta (UNINTA) que oferece 29 cursos de graduação e Faculdade Luciano Feijão com oferta de cinco cursos de graduação. Lojas de produtos de informática, com filiais de lojas de Fortaleza como a Ibyte e computer store, sendo o destaque para a empresa Execute implantada em 1995 no mesmo ano em que a UVA passou o ofertar novos cursos, inclusive graduação em computação, enfim muitas lojas desse segmento se espalham pelo centro da cidade. Os cursos de idiomas totalizam sete, alguns estrategicamente próximos as instituições de ensino superior, o Curso Wiil idiomas e Cursos de Língua Estrangeira 
(CLE) são cursos não franquedados; Palácio de Ciências e Línguas Estrangeiras mantido pela Prefeitura de Sobral, já os cursos de franquias são: Fisk, CNA, Yazigi Sobral, Wizard Sobral,

Sobral no presente figura como um dos centros médios importantes do nordeste brasileiro, atraindo desde meados dos anos de 1990 investimentos industriais nacionais no bojo dessas (re) configurações do mapa industrial. Seu Patrimônio Histórico foi (re)valorizado juntamente com uma significativa reforma urbana, como resultante dos novos papéis pensados para as cidades médias Brasileiras.

Parnaíba cidade mais relevante do estado do Piauí depois da capital, Teresina, apresenta características semelhantes a Sobral no que concerne a urbanização e a dinâmica de sua população. Situada no Delta do Parnaíba, área de grande potencial turístico encontra na mesma uma das possibilidades de desenvolvimento no presente.

Acreditamos que existem novas dinâmicas territoriais em curso, cabendo o desenvolvimento de pesquisas que evidenciem a existência das mesmas. A presente reflexão se insere em uma temática maior compreendendo os estudos urbanos e territoriais, cujo resultado esperado é produzir conhecimentos. Almeja-se, ainda, através da prática de pesquisa contribuir para um maior aprimoramento na formação dos estudantes de graduação e pósgraduação e para a socialização de saberes que possam subsidiar ações propositivas e políticas públicas.

\section{REFERÊNCIAS}

ALBUQUERQUE, Roberto C. de. A universidade e o nordeste. In ANDRADE, Antonio Cabral de et all. A Universidade e o Desenvolvimento Regional. Fortaleza: Edições UFC, 1980.

AMORA, Zenilde. B. Cidades Médias: a busca de uma definição. AGB - XIII Encontro Nacional de Geógrafos, Por uma Geografia Nova na construção do Brasil. 2002. João Pessoa. ANAIS. João Pessoa, 2002. CD 1.

Maria C. L. Olhando o mar do sertão: a lógica das cidades médias no Ceará. In: SPOSITO, Maria Encarnação Beltrão (Org.). Cidades médias: espaços em transição. 1 ed. São Paulo: Expressão popular, 2007, p. 343-378.

ANDRADE, T. A. e Serra, R. V. Crescimento Econômico nas cidades médias brasileiras. Rio de Janeiro: IPEA, nº 592, 1998 b. (Coleção texto para discussão).

ANDRADE, T. A. e SERRA, R. V. O recente desempenho das cidades médias no crescimento populacional urbano brasileiro. Rio de Janeiro: IPEA, $\mathrm{n}^{\circ}$ 554, 1998 a. (Coleção texto para discussão) 
BARAT, Josef. Introdução aos problemas urbanos brasileiros: teoria, análise e formulação de política. Rio de Janeiro, Editora Campus, 1979.

BAUMGARTNER, Wendel Henrique. Universidades Públicas Como Agentes de Desenvolvimento Urbano e Regional de Cidades Médias e Pequenas: Uma Discussão Teórica, Metodológica e Empírica. Geotextos (Online), v. 11, p. 91-111, 2015.

BRUNET, Roger. Villes Moyennes: point de vue de géographe. In: COMMERÇON, N. GOUJON, P. (dir) Villes moyennes: espace, societé, patrimoine. Lyon, Presse Universitaire de Lyon, 1997.

CAMPOS, Francisca das Chagas Lopes. Campus Ministro Reis Velloso (UFPI): história e memória. / Teresina: Dissertação (Mestrado em Educação) UFPI. 2010. 280 fls.

CARLOS, Ana F. A. Uma leitura sobre a cidade. In: Cidades: Revista Científica/Grupo de Estudos Urbanos. V. 1, nº 1, 2004. Presidente Prudente: Grupo de Estudos Urbanos, 2004.

COMMERÇON, Nicole. La dynamique du changement em ville moyenne: Chalon, Mâcon, Bourg. Lyon, Presses Universitaire de Lyon, 1998.

CORRÊA, Roberto L. Construindo o conceito de cidade média. In: SPOSITO, Maria Encarnação Beltrão (Org.). Cidades médias: espaços em transição. 1 ed. São Paulo: Expressão popular, 2007, p. 23-34.

FREIRE, H. P. O uso do território de Sobral - Ceará pelas instituições de ensino superior. Dissertação (Mestrado acadêmico em Geografia). Universidade Estadual do Ceará. Fortaleza: 2011. $112 \mathrm{p}$.

GOMES, Rita de Cássia da Conceição; SILVA, Anieres Barbosa da ; SILVA . Pequenas Cidades: uma abordagem geográfica. 1. ed. Natal/RN: EDUFRN - Editora da Universidade Federal do do Rio Grande do Norte, 2009. v. 1.

LAMARRE, Christine. Ville Moyenne: naissance d'um concept. In: COMMERÇON, N. GOUJON P. (dir) Villes moyennes: espace, societé, patrimoine. Lyon, Presses Universitaire de Lyon, 1997.

Mota, Adeir Archanjo. A geografia do ensino superior de Maringá: a dinâmica regional e as transformações no espaço urbano. Universidade Estadual de Maringá (UEM). Maringá, PR : [s.n.], 2007. $264 \mathrm{f}$.

PONTES, Beatriz M. S. As mudanças no processo produtivo capitalista e suas repercussões nas cidades médias nordestinas. In: Cidades médias: produção do espaço urbano regional.

SPOSITO, M. Encarnação Beltrão. As cidades médias e os contextos econômicos contemporâneos. In: SPOSITO, Maria Encarnação Beltrão (Org.). Urbanização e cidades: perspectivas geográficas. Presidente Prudente: UNESP. 2001.

(2007). Cidades médias: reestruturação das cidades e reestruturação urbana. In: Maria Encarnação Beltrão Sposito. (Org.). Cidades médias: espaços em transição. 1ed.São Paulo: Expressão Popular. v. 1, p. 233-253

SANTOS, Milton. A urbanização brasileira. $2^{a}$ ed. São Paulo, HUCITEC, 1994. 
SILVEIRA, Maria Laura. O Ensino Superior e Particular e o Território Brasileiro. 1.ed. Brasília: ABMES, 2000.

SOJA, Edward W. Geografias pós- modernas: a reafirmação do espaço na teoria social crítica. Tradução Vera Ribeiro. Rio de Janeiro: Zahar Ed., 1983

TOMAS, François (Coord.). Les villes moyennes em Amerique Latine. Ateliers de Caravelle. Salamanca - Espanha, 1998.

Recebido em Outubro de 2017

Aprovado em Maio de 2018

Publicado em Julho de 2018 